\title{
1 Early bursts of diversification defined the faunal colonization of land
}

2

3 Nicholas J. Minter ${ }^{1, *}$, Luis A. Buatois ${ }^{2}$, M. Gabriela Mángano ${ }^{2}$, Neil S. Davies ${ }^{3}$, Martin R.

4 Gibling $^{4}$, Robert B. MacNaughton ${ }^{5}$, and Conrad C. Labandeira ${ }^{6-8}$

5

$6{ }^{1}$ School of Earth and Environmental Sciences, University of Portsmouth, Portsmouth,

7 Hampshire PO1 3QL, UK. ${ }^{2}$ Department of Geological Sciences, University of Saskatchewan,

8 Saskatoon, Saskatchewan S7N 5E2, Canada. ${ }^{3}$ Department of Earth Sciences, University of

9 Cambridge, Cambridge, Cambridgeshire CB2 3EQ, UK. ${ }^{4}$ Department of Earth Sciences,

10 Dalhousie University, Halifax, Nova Scotia B3H 4R2, Canada. ${ }^{5}$ Geological Survey of

11 Canada (Calgary), Natural Resources Canada, Calgary, Alberta T2L 2A7, Canada.

$12{ }^{6}$ Department of Paleobiology, Smithsonian Institution, Washington DC 20013-7012, USA.

$13{ }^{7}$ Department of Entomology and BEES Program, University of Maryland, College Park,

14 Maryland 21740, USA. ${ }^{8}$ College of Life Sciences, Capital Normal University, Beijing

15 100048, China. *Correspondence and requests for materials should be addressed to N.J.M.

16 (email: nic.minter@port.ac.uk). 


\section{Abstract}

21 The colonization of land was one of the major events in Earth history, leading to the

22 expansion of life and laying the foundations for the modern biosphere. We examined trace

23 fossils, the record of the activities of past life, to understand how animals diversify both

24 behaviourally and ecologically when colonizing new habitats. The faunal invasion of land was preceded by excursions of benthic animals into very shallow, marginal-marine environments during the latest Ediacaran Period and culminated in widespread colonization of non-marine niches by the end of the Carboniferous Period. Trace-fossil evidence for the colonization of new environments shows repeated early-burst patterns of maximal ichnodisparity (the degree of difference among basic trace-fossil architectural designs), ecospace occupation, and level of ecosystem engineering prior to maximal ichnodiversity. Similarities across different environments in the types of behavioural programmes employed (as represented by different trace fossils), modes of life present, and the ways in which animals impacted their environments, suggest constraints on behavioural and ecological diversification. The early-burst patterns have the hallmark of novelty events. The underlying drivers of these events likely were the extrinsic limitation of available ecospace and intrinsic controls of genomic and developmental plasticity that enabled trace-maker morphological

37 and behavioural novelty. 
The colonization of land by animals was a fundamental transition in the development of the biosphere $^{1}$. The initial colonization of each new continental environment during the Palaeozoic may be viewed as a series of repeated experiments that allowed the morphological, behavioural, and ecological penetration of ecospace during successive evolutionary radiations. Preceding faunal colonization, a diverse continental microbiota of prokaryotes and eukaryotes existed during the Precambrian, as evidenced by molecular clocks $^{2}$, microbially induced sedimentary structures ${ }^{3}$, microfossils $^{4-6}$, and various proxies ${ }^{7-9}$. However, such microbially-based communities were physically-passive occupants of quiescent patches within landscapes ${ }^{10}$, and later were joined during the Cambrian and Ordovician by fungi ${ }^{11}$ and land plants ${ }^{12}$, which had ecosystem engineering capabilities.

Continental habitats thus were relatively well-established before their invasion by motile ecosystem engineers (i.e. animals), but debate surrounds the timing and palaeoenvironmental context of this invasion in the history of life ${ }^{13,14}$. Molecular clock studies increasingly point to a Precambrian-Middle Cambrian origin for myriapods ${ }^{15-17}$, a Cambrian-Ordovician origin for $\operatorname{arachnids}^{15,16}$, and an Ordovician origin for hexapods ${ }^{15,16,18}$, and argue for initial colonization of land by these groups during the Cambrian (myriapods), Ordovician-Silurian (arachnids) and Ordovician (hexapods) ${ }^{16}$. These estimates agree with the oldest known body fossils of arachnids (Silurian) ${ }^{16}$ but pre-date the oldest known terrestrial myriapods (mid Silurian) ${ }^{16}$ and hexapods (Early Devonian) ${ }^{18}$. Trace fossils (known also as ichnofossils: the burrows, trails and trackways left behind by the activities of animals) provide a unique, but complementary, alternative record to molecular clock or body fossil data that further refines our understanding of the advent of motile life on land ${ }^{19-22}$. The oldest known non-marine trackways, from rocks of Middle-Late Cambrian age ${ }^{20}$, include those of a myriapod-like animal that are more 
congruent with molecular clock estimates of terrestrial myriapod origins. In addition to commonly pre-dating body fossils of their inferred producers, trace-fossil archives of animal behaviour: (i) record the activities of both soft- and hard-bodied organisms; (ii) provide in situ evidence and precise environmental contexts of animal habitats; and (iii) may represent archetypal, sediment-modifying, ecosystem engineers, altering their environment in ways that affect other organisms ${ }^{23}$ with potential macroevolutionary consequences ${ }^{24}$. focus on the relationship through time between disparity (range of morphological variety) and taxonomic diversity (number of taxa, typically assessed at the family or genus level). Most studies reveal a "disparity first" pattern, whereby an early burst in morphological diversification produces maximal disparity early within a lineage ${ }^{25-27}$, followed by a subsequent and pronounced rise in taxonomic diversity after a significant time interval. This contrasts with a null pattern wherein disparity and diversity are approximately coupled, and a "diversity first" pattern where disparity initially is constrained and exceeded by taxonomic diversification ${ }^{25-27}$. Here, we present a new framework for macroevolutionary analysis of behavioural diversification ${ }^{28}$, ecospace occupation, and ecosystem engineering ${ }^{29}$. This new approach allows: (i) analysis of the timings of colonization of different continental environments; (ii) identification of commonalities and differences in patterns of behavioural and ecological diversification across continental environments during the colonization of land; and (iii) elucidation of causative macroevolutionary processes. Behaviour is just as integral to organismal phenotype as is morphology $y^{23}$. Consequently, analyses of disparity and diversity can be extended to behaviour through the concepts of ichnodisparity and ichnodiversity. Ichnodiversity is a measure of ichnotaxonomic richness. Ichnotaxa are

91 biogenic sedimentary structures formally classified on the basis of their morphology as a

92 reflection of tracemaker behaviour. By contrast, ichnodisparity is a measure of the variability 
93 of trace-fossil morphological plans, quantified as the number of architectural designs, such as simple horizontal trails or vertical unbranched burrows ${ }^{28}$. Architectural designs reflect broad behavioural programmes, wherein variations are represented by a variety of ichnotaxa. The amount of occupied ecospace is quantified as the number of modes of life, and the amount of ecosystem engineering is quantified as the number of ichnological impacts upon a sedimentary stratum. These concepts are intended to foster a commonality of language and analysis between ichnologists and benthic ecologists. The results below are based on an exhaustive search of published accounts of Palaeozoic trace fossils worldwide. Caveats regarding strengths and limitations of trace-fossil analysis are discussed in the Methods and

102 Results sections.

\section{Results}

Continental and shallow marginal-marine trace-fossil record. Subaqueous coastal (Fig.

107 1), transitional coastal (Fig. 2), and transitional alluvial environments (Fig. 3) have the most extensive and complete Palaeozoic trace-fossil records of the environments considered in this study. The trace-fossil records for other environments are incomplete and trends should be treated cautiously (Supplementary Figs 1-6). Data from at least one geological period are

111 lacking for subaerial coastal, subaqueous alluvial, aeolian, and ephemeral lacustrine environments. Subaqueous lacustrine and marginal lacustrine environments are represented only by a short interval of occupation within the temporal scope of this study.

115 observed ichnodiversity and the independent sampling measure of terrestrial clastic rock

116 volume when data are considered at both sub-period and period levels for subaqueous

117 coastal, transitional coastal, and transitional alluvial environments (Supplementary Table 1). 
118 There are statistically significant correlations (Bonferroni corrected $\alpha^{\prime}$-level for multiple

119 comparisons $=0.0167$ ) between observed ichnodiversity and the numbers of trace-fossil-

120 bearing formations and/or the numbers of trace-fossil assemblages when the data are pooled

121 by geological sub-period, but not when data are pooled by geological period (Supplementary

122 Table 1). At the sub-period level, low observed values for ichnodiversity are associated with

123 low numbers of trace-fossil bearing formations and trace-fossil assemblages (Supplementary

124 Fig. 7). This relationship may reflect observed ichnodiversity being driven by the number of

125 formations (the bias model), ichnodiversity driving the number of discovered formations (the

126 redundancy model), or a combination of these effects ${ }^{30}$. There clearly is a trade-off between

127 temporal resolution and the overall reliability of observed patterns. Ichnodiversity trajectories

128 are strongly related to sampling intensity at the sub-period level, but this effect is dampened

129 when data are pooled into geological periods, as is done for presentation, analysis and

130 discussion of data in this study.

131 At the level of the geological period, there are no statistically significant correlations

132 (Bonferroni corrected $\alpha^{\prime}$-level $=0.0167$ ) amongst the diversity measures of ichnodiversity,

133 ichnodisparity, ecospace occupation and ecosystem engineering versus the sampling

134 measures of the numbers of trace-fossil bearing formations and trace-fossil assemblages

135 (Supplementary Table 2). Rank-order correlation plots identify those geological periods with

136 the lowest residuals from the fitted models (Supplementary Figs 8-10), and for which

137 diversification metrics are most closely related with sampling intensity. Decreases in

138 ichnodiversity observed for Devonian and Permian subaqueous coastal environments

139 probably are constrained by the number of trace-fossil bearing formations. This relationship

140 also explains the decrease in ichnodisparity for Permian subaqueous coastal environments.

141 Increases in ichnodisparity during the Devonian and in ecosystem engineering for Cambrian

142 transitional coastal environments probably are related to greater sampling intensity. Some 
143 observed values may be underestimates and might be greater with comparable sampling

144 intensity. These analyses identify limitations to the trace-fossil record of continental and

145 shallow marginal-marine environments, but the limitations do not compromise the overall

146 patterns.

147

148 Patterns of behavioural and ecological diversification. By the end of the geological period

149 following initial colonization of a particular continental environment (e.g. transitional alluvial

150 environments by the end of the Silurian), global ichnodisparity, ecospace occupation and

151 ecosystem engineering began to reach a plateau with little subsequent numerical or

152 compositional change. Although ichnodiversity shows greater variation (Figs 1-3,

153 Supplementary Figs 1-6), this does not affect the overall pattern of requiring additional time

154 to achieve an asymptote or continuation of an increase across the temporal range of this

155 study. Variation from these trends in observed ichnodiversity is attributable to sampling

156 intensity (Supplementary Figs 7-10; Supplementary Table 2). In transitional alluvial

157 environments, ichnodiversity follows an approximately linear increase from the Ordovician

158 to Permian, and shows no sign of reaching an asymptote within the temporal range of this

159 study (Fig. 3). However, the Devonian has one of the greater numbers of trace-fossil bearing

160 formations for transitional alluvial environments, and observed ichnodiversity during the

161 Ordovician, Silurian and Permian may be limited by the lower number of trace-fossil bearing

162 formations (Supplementary Fig 7f). Global ichnodisparity, ecospace occupation and

163 ecosystem engineering rose sharply from the Ediacaran to Cambrian in subaqueous and

164 transitional coastal environments before becoming fairly constant through the rest of the

165 Palaeozoic. This pattern is similar for transitional alluvial environments, with initial

166 colonization during the Ordovician, reaching an asymptote by the end of the Silurian. 
Initial infaunal occupation was limited to shallow and semi-infaunal tiers, respectively, in subaqueous coastal and transitional coastal environments. Facultatively motile, suspension-feeding animals created horizontal to obliquely inclined burrows in subaqueous coastal environments, whereas freely motile, non-specialized deposit-feeding animals were responsible for making horizontal burrows with horizontal to vertical branches in transitional coastal environments. Each type of structure was produced by compressional forces and acted as gallery biodiffusive structures (Figs 1,2), in which sediment particles may be rapidly redistributed from one part of the sediment profile to another. Transitional alluvial environments initially were colonized by freely motile, non-specialized deposit-feeding animals and possible predators occupying the surficial tier. These colonizers left trackways and scratch imprints that had minimal, compressive, biodiffusive impact upon the sediment (Fig. 3).

Occupation of the deep infaunal tiers of subaqueous coastal, transitional coastal, and transitional alluvial environments continued during the geological interval following initial colonization and were dominated by facultatively motile suspension-feeding animals and possible predators. Such infaunal organisms used compression of the sediment to create stable, vertical, unbranched and single U- and Y-shaped burrows that acted as gallery biodiffusive structures. The same types of structure also were produced at this time and subsequently further expanded into the shallow and intermediate-level infaunal tiers. In transitional coastal and transitional alluvial environments, the deep infaunal tier also was colonized by freely motile, non-specialized deposit-feeding animals. In transitional coastal environments, organisms of this tier created burrows with complexly oriented spreiten; by contrast, in transitional alluvial environments they created simple, actively filled (meniscate), horizontal to obliquely inclined structures. Both types of architectural design were produced by animals moving through the sediment by backfilling and transporting sediment in a 
manner similar to a conveyor belt. With the exception of subaerial coastal environments where colonization was limited to the surficial tier (Supplementary Fig. 1), expansion to the deep infaunal tier in other environments occurred within the geological period of initial invasion (Supplementary Figs 2,3,6) or the following period (Supplementary Figs 4,5). Modes of life increased in number for other tiers of subaqueous coastal, transitional coastal, and transitional alluvial environments in the geological period following initial colonization. Freely motile, non-specialized and specialized deposit-feeding animals and predators colonized the semi-infaunal tier. Among other activities, they were responsible for: (i) movement by backfilling and acting as sediment conveyors to produce simple horizontal trails; (ii) use of compression to produce horizontal burrows with horizontal to vertical branches that acted as gallery biodiffusive structures; and (iii) excavation and regeneration of sediment from below the sediment-water interface during the production of bilobate trails and paired grooves, and bilaterally symmetrical short, scratched imprints. The process of regeneration provides sediment for transportation by physical processes. The shallow infaunal tier was colonized by freely motile, non-specialized deposit feeders and possible predators that moved by backfilling as they acted as sediment conveyors in the production of simple, actively filled, massive and meniscate, horizontal to obliquely inclined structures. The number of ichnogenera within each architectural design for each tier remains

210 fairly constant across the swath of geological time represented by each environmental

211 category. However, for the surficial tier, there is a greater increase in ichnodiversity compared to ichnodisparity. This pattern is most pronounced in transitional alluvial

213 environments (Fig. 4; Supplementary Fig. 11). Principal co-ordinates analyses show that

214 architectural designs, modes of life, and impacts upon the sediment are remarkably consistent 215 through time and across environments (Supplementary Fig. 12). 


\section{Discussion}

219 The prologue to the colonization of land by animals began during the latest Ediacaran and

220 was limited to subaqueous and transitional coastal environments. During the Cambrian, some

221 animals, principally arthropods, were capable of making amphibious excursions into

222 subaerial coastal environments ${ }^{20}$. The first evidence of animals in fully continental settings possibly occurs during the Ordovician ${ }^{31}$, although this may be questionable ${ }^{14}$. These events were followed by expansion of animals, plants and fungi into subaqueous alluvial and ephemeral freshwater environments during the Silurian ${ }^{32}$. The Devonian records the first trace-fossil evidence of organisms inhabiting aeolian environments ${ }^{33}$ and lake margins ${ }^{34}$.

Subaqueous environments in the centres of deep lakes were not colonized until the Carboniferous $^{19}$. These data support a marine route for the colonization of land, via transitional coastal environments into subaerial coastal and transitional alluvial environments before subaqueous alluvial and ephemeral lacustrine environments were colonized, followed by aeolian and marginal lacustrine environments, and finally subaqueous lacustrine environments.

Environmental expansion was coupled with increases in several parameters. In

234 general, ichnodisparity, the volume of occupied ecospace, and the level of ecosystem engineering reached a plateau soon after colonization of a new environment, with little

236 subsequent change for the duration of the Palaeozoic. The trend for global ichnodiversity is more variable, taking longer to reach a plateau in many environments and also exhibiting intervals of apparently decreasing ichnodiversity. In transitional alluvial environments,

239 ichnodiversity increases linearly from the Ordovician to Permian, whereas ichnodisparity,

240 occupied ecospace and ecosystem engineering reached asymptotes from the Silurian to

241 Devonian. The decoupling between ichnodiversity and ichnodisparity is exaggerated during 
this interval, attributable to increasing numbers of surficial tier trackway and scratch imprint ichnogenera. This increase is in part a function of the diversification of trace-making organisms that produce trackways and scratch imprints because the morphology of these ichnogenera is strongly influenced by the anatomy of the producer. In addition, the paucity of deep-tier bioturbators may have increased the preservation potential of trackways and other trace fossils formed at the sediment surface.

There is strong trace-fossil evidence that Cambrian arthropods and mollusks had begun to adapt to marginal-marine settings. One or more lineages of annelids, nematodes and nemerteans also may have exhibited adaptation to this environment. A range of arthropods was responsible for trackways and scratch imprints, including trilobites, aglaspidids, chasmataspidids, and marellamorphs in shallow marginal-marine environments, as well as myriapod-like animals and euthycarcinoids in subaerial coastal environments. Trilobites were the most likely producers of bilobate trails and paired grooves, and bilaterally symmetrical, short, scratched impressions and burrows in marginal-marine settings ${ }^{35}$. Oval imprints and trails with undulating transverse bars and furrows likely were produced by mollusks. Wormlike animals and possibly crustaceans were responsible for a variety of burrows and trails. Infaunal cnidarians likely also were present and produced vertical plug-shaped burrows in marginal-marine environments. Chordates appeared during the Ordovician, with body fossils

260 of early fish lineages preserved in coastal settings ${ }^{36}$. Possible trace-fossil evidence in the form 261 of flattened trilobate trails, affiliated with flatworms is present in Ordovician strata ${ }^{36}$. Many of the body fossils of terrestrial arthropod, fungal, and plant lineages appear initially during

263 the latter part of the Silurian ${ }^{32}$, including the earliest representatives of at least five major

264 groups of chelicerate and myriapodan arthropods that became prominent later in the

265 Palaeozoic: scorpions, trigonotarbid arachnids, arthropleurids, kampecarid millipedes, and 266 centipedes $^{32,37}$. Trackways likely produced by members of these arthropod groups 
(Diplichnites, Paleohelcura) are known from a variety of Silurian marine littoral and terrestrial environments ${ }^{38,39}$. Sister-group relationships suggest a marine route for myriapods and $\operatorname{arachnids}^{16}$, which is consistent with the oldest known trace fossils for these groups respectively occurring from Cambrian ${ }^{20}$ and Silurian ${ }^{39}$ transitional coastal environments.

Whether hexapods colonized the land via a marine or freshwater route is dependent upon the identity of their sister group, which currently is unresolved ${ }^{16}$. Hexapods are first recorded during the Early Devonian ${ }^{18,37}$. Trackways attributable to apterygote insects (Stiaria) have been described from Devonian alluvial and lacustrine environments ${ }^{34,40}$ and possibly from Silurian transitional coastal environments ${ }^{40,41}$, although they may have been produced by a scorpionid $^{41}$.

Microbially induced sedimentary structures occurred in association with many trace fossils in early emergent tidal-flat settings, and microbial mats could have provided a food source for the above-mentioned animals. In addition, microbial mats likely increased tracefossil preservation potential ${ }^{42}$. Similarly, early land plants potentially could have provided a source of nutrients for pioneer continental metazoans in the earliest, simple, terrestrial food webs $^{32,37}$. The search for food and lack of competition for terrestrial organic matter may have spurred the earliest stages in the colonization of land. Another likely initial driver of terrestrialization was predator avoidance ${ }^{37}$. Reproduction, particularly for establishment of mating sites, has been suggested as an alternative hypothesis ${ }^{22}$. In addition to these potential causative mechanisms, the colonization of continental environments took place during an interval of Earth history when landscapes were being fundamentally and irreversibly altered by land-plant evolution. Until the Silurian, colonization occurred among landscapes that were dominated by unconfined, braided alluvial systems. The rise of land plants expanded the variety of fluvial styles, including the first mixed sand-mud meandering rivers by the end of the Silurian ${ }^{43,44}$. This increase in alluvial geomorphological and sedimentary diversity 
292 increased the potential physical habitats for biotas through the latest Palaeozoic ${ }^{45}$, and

293 ecological studies of modern alluvial environments show that biodiversity increases toward

294 more geomorphologically complex reaches of river systems ${ }^{46}$. The increasing variety of

295 continental landscapes is stratigraphically consistent with the first appearances of continental

296 ichnofaunas, followed thereafter by their subsequent expansion and diversification.

297 Adaptive radiations sensu stricto correspond to portions of evolutionary radiations

298 that involve a single clade ${ }^{47}$. An early-burst, "disparity first" pattern is most prevalent

299 amongst studies based on single clades of body fossils ${ }^{25-27}$. The colonization of each

300 continental environment recorded by trace fossils occurred across independent animal

301 lineages. Novelty events and broad diversification events are two types of evolutionary

302 radiation that involve independent lineages, with novelty events demonstrating a "disparity

303 first" pattern, and broad diversification events a "diversity first" pattern ${ }^{47}$. With minor

304 exceptions, the phyla involved in subsequent waves of colonization during the later

305 Palaeozoic largely were the same as the founding colonists during the mid Palaeozoic. The

306 colonization of each new continental environment therefore may be viewed broadly as a

307 series of repeated-measures experiments through which commonalities and differences in the

308 exploration and occupation of ecospace can be analyzed. Despite differing environmental

309 contexts, the results of each colonization event are largely similar, characterized by initial

310 rapid realization of maximal ichnodisparity and a later increase in ichnodiversity. This pattern

311 conforms to an early-burst model ${ }^{47}$. Maximal numbers of architectural designs, modes of life,

312 and ichnological sediment impacts appear to have arisen rapidly but diachronously across

313 continental environments, once they were colonized. Except for the first geological period of

314 occupation, the constituent architectural designs, modes of life, and ichnological sediment

315 impacts are remarkably similar across time and environments (Supplementary Fig. 12). The

316 colonization of different continental environments therefore has the hallmark of "novelty 
317 events" associated with evolutionary radiations. A similar early-burst relationship between

318 ichnodisparity and ichnodiversity has been documented for marine softgrounds and

319 hardgrounds, respectively, following their initial colonization during the Cambrian Explosion 320 and Great Ordovician Biodiversification Event ${ }^{28}$.

$321 \quad$ Two principal process models have been proposed to explain disparity-first

322 diversification patterns. The first is the ecospace model, whereby the success of new forms is 323 controlled by variation in ecological opportunities. The second is the genetic/developmental 324 model, whereby increasing genetic/developmental constraints reduce the potential for 325 innovation through time ${ }^{27,47}$. Most studies support the ecospace model, with exploitation of 326 new ecological opportunities following colonization of a new environment or by ecological 327 release after a mass extinction that leads to rapidly increasing disparity ${ }^{47}$. However, in one 328 clade of vertebrates, disparity was found to decline throughout the Permian and Triassic and 329 did not return to pre-extinction levels, whereas taxonomic diversity decreased at the boundary 330 but afterwards rebounded ${ }^{48}$. This supports the genetic/developmental hypothesis whereby the 331 capacity of the clade to generate disparate life forms was reduced by the genetic bottleneck 332 induced by the Permo-Triassic mass extinction ${ }^{48}$. However, the ecospace and genetic/developmental models are not necessarily mutually exclusive ${ }^{47}$, particularly as certain

334 genetic abilities are required to generate varied forms to exploit and create ecological 335 opportunities. Indeed, novelty events are enabled by the combination of extrinsic control of 336 available ecospace and intrinsic control of sufficient genomic and developmental plasticity to 337 allow phenotypic novelty ${ }^{26,47}$. This enablement occurred through both morphology and 338 behaviour. Our results show that largely the same architectural designs, modes of life, and 340 ichnological sediment impacts occur across subaqueous coastal, transitional coastal, and 341 transitional alluvial environments (Figs 1-3; Supplementary Fig. 12). This suggests some 
constraints on the behavioural and ecological roles fulfilled by independent groups of organisms within continental environments. It remains to be investigated if these are "local maxima" for the Palaeozoic and what trends occurred during the Mesozoic and Cenozoic with such events as the evolution of social insects ${ }^{49}$ and the Mesozoic Lacustrine Revolution $^{50}$. With an evolutionary experiment that ran its course several times, a pattern emerges that is characterized by: (i) colonization of a new environment; (ii) relatively rapid infilling of available ecospace through modification of the environment by the activities of animals; (iii) diversification of new behavioural programmes expressed as new trace-fossil architectural designs; and (iv) diversification of ichnogenera within already occupied ecospace representing variation on previously established, behavioural themes.

\section{References}

1. Maynard Smith, J. \& Szathmáry, E. The Major Transitions in Evolution (WH Freeman, 1995).

2. Battistuzzi, F. U., Feijao, A. \& Hedges, S. B. A genomic timescale of prokaryote evolution: Insights into the origin of methanogenesis, phototrophy, and the colonization of land. BMC Evol. Biol. 4, 44 (2004).

3. Davies, N. S., Liu, A. G., Gibling, M. R. \& Miller, R. F. Resolving MISS conceptions and misconceptions: A geological approach to sedimentary surface textures generated by microbial and abiotic processes. Earth-Sci.Rev. 154, 210-246 (2016).

4. Horodyski, R. J. \& Knauth, L. P. Life on land in the Precambrian. Science 263, 494-498 (1994).

5. Strother, P. K., Battison, L., Brasier, M. D. \& Wellman, C. H. Earth's earliest non-marine eukaryotes. Nature 473, 505-509 (2011). 
366

367

368

369

370

371

372

373

374

375

376

377

378

379

380

381

382

383

384

385

386

387

388

389

390

6. Wellman, C. H. \& Strother, P. K. The terrestrial biota prior to the origin of land plants (embryophytes): A review of the evidence. Palaeontology 58, 601-627 (2015).

7. Watanabe, Y., Martini, J. E. J. \& Ohmoto, H. Geochemical evidence for terrestrial ecosystems 2.6 billion years ago. Nature 408, 574-578 (2000).

8. Knauth, L.P. \& Kennedy, M. J. The late Precambrian greening of the Earth. Nature 460, 728-732 (2009).

9. Kennedy, M., Droser, M., Mayer, L. M., Pevear, D. \& Mrofka, D. Late Precambrian oxygenation; inception of the clay mineral factory. Science 311, 1446-1449 (2006).

10. McMahon, W. J., Davies, N. S. \& Went, D. J. Negligible microbial matground influence on pre-vegetation river functioning: evidence from the Ediacaran-Lower Cambrian Series Rouge, France. Precambrian Res. 292, 13-34 (2017).

11. Horodyskyj, L. B., White, T. S. \& Kump, L. R. Substantial biologically mediated phosphorus depletion from the surface of a Middle Cambrian paleosol. Geology 40, 503$506(2012)$

12. Rubinstein, C. V., Gerrienne, P., de la Puente, G. S., Astini, R. A. \& Steemans, P. Early Middle Ordovician evidence for land plants in Argentina (eastern Gondwana). New Phytol. 188, 365-369 (2010).

13. Retallack, G. J. Ediacaran life on land. Nature 493, 89-92 (2013).

14. Minter, N. J. et al. in The Trace-Fossil Record of Major Evolutionary Events, Vol. 1. (eds Mángano, M. G. \& Buatois, L. A.) 157-204 (Springer, 2016a).

15. Rota-Stabelli, O., Daley, A. C. \& Pisani, D. Molecular timetrees reveal a Cambrian colonization of land and a new scenario for ecdysozoan evolution. Curr. Biol. 23, 392398 (2013).

16. Lozano-Fernandez, J. et al. A molecular palaeobiological exploration of arthropod terrestrialization. Phil. Trans. R. Soc. B 317, 20150133 (2016). 
391 17. Fernández, R., Edgecombe, G. D. \& Giribet, G. Exploring phylogenetic relationships

392 within Myriapoda and the effects of matrix composition and occupancy on phylogenomic 393 reconstruction. Syst. Biol. 65, 871-889 (2016).

394 18. Misof, B. et al. Phylogenomics resolves the timing and pattern of insect evolution.

$395 \quad$ Science 346, 763-767 (2014).

396 19. Buatois, L. A. \& Mángano, M. G. Ecospace utilization, paleoenvironmental trends, and 397 the evolution of early nonmarine biotas. Geology 21, 595-598 (1993).

20. MacNaughton, R. B. et al. First steps on land: Arthropod trackways in CambrianOrdovician eolian sandstone, southeastern Ontario, Canada. Geology 30, 391-394 (2002).

21. Miller, M. F. \& Labandeira, C. C. Slow crawl across the salinity divide: Delayed colonization of freshwater ecosystems by invertebrates. GSA Today 12(12), 4-10 (2002).

22. Braddy, S. J. Ichnological evidence for the arthropod invasion of land. Foss. Strat. 51, 136-140 (2004).

23. Jones, C. G., Lawton, J. H. \& Shachak, M. Organisms as ecosystem engineers. Oikos 69, 373-386 (1994).

24. Erwin, D. H. Macroevolution of ecosystem engineering, niche construction and diversity. Trends Ecol.Evol. 23, 304-310 (2008).

25. Foote, M. Discordance and concordance between morphological and taxonomic diversity. Paleobiology 19, 185-204 (1993).

410 26. Erwin, D. H. Disparity: Morphological pattern and developmental context. Palaeontology $411 \quad 50,57-73(2007)$.

412 27. Benton, M. J. Exploring macroevolution using modern and fossil data. Proc. R. Soc. Lond. B 282, 20150569 (2015). 
28. Buatois, L. A., Mángano, M. G., Olea, R. A. \& Wilson, M. A. Decoupled evolution of soft and hard substrate communities during the Cambrian Explosion and Great Ordovician Biodiversification Event. Proc. Natl. Acad. Sci. USA 113, 6945-6948 (2016).

29. Minter, N. J., Buatois, L. A. \& Mángano, M. G. in The Trace-Fossil Record of Major Evolutionary Events, Vol. 1. (eds Mángano, M. G. \& Buatois, L. A.) 1-26 (Springer, 2016b).

30. Benton, M. J. Palaeodiversity and formation counts: Redundancy or bias? Palaeontology 58, 1003-1029 (2015).

31. Johnson, E. W., Briggs, D. E. G., Suthren, R. J., Wright, J. L. \& Tunnicliff, S. P. Nonmarine arthropod traces from the subaerial Ordovician Borrowdale Volcanic Group, English Lake District. Geol. Mag. 131, 395-406 (1994).

32. Labandeira, C. C. Invasion of the continents: Cyanobacterial crusts to tree-inhabiting arthropods. Trends Ecol. Evol. 20, 253-262 (2005).

33. Morrissey, L. B., Braddy, S. J., Dodd, C., Higgs, K. T. \& Williams, B. P. J. Trace fossils and palaeoenvironments of the Middle Devonian Caherbla Group, Dingle Peninsula, southwest Ireland. Geol. J. 47, 1-29 (2012).

34. Walker, E. F. Arthropod ichnofauna of the Old Red Sandstone at Dunure and Montrose, Scotland. T. Roy. Soc. Edin. Ear. Sci. 76, 287-297 (1985).

35. Mángano, M. G., Buatois, L. A., Astini, R. \& Rindsberg, A. K. Trilobites in early Cambrian tidal flats and the landward expansion of the Cambrian explosion. Geology 42, 143-146 (2014).

36. Davies, N. S., Sansom, I. J., Albanesi, G. L. \& Cespedes, R. Ichnology, palaeoecology and taphonomy of an Ordovician vertebrate habitat: The Anzaldo Formation, central Bolivia. Palaeogeogr. Palaeoclimatol. Palaeoecol. 249, 18-35 (2007). 
37. Shear, W. A. \& Kukalová-Peck, J. The ecology of Paleozoic terrestrial arthropods: The fossil evidence. Can. J. Zool. 68, 1807-1834 (1990).

38. Wright, J. L., Quinn, L., Briggs, D. E. G. \& Williams, S. H. A subaerial arthropod trackway from the Upper Silurian Clam Bank Formation of Newfoundland. Can. J. Earth Sci. 32, 304-313 (1995).

39. Marriott, S. B., Morrissey, L. B. \& Hillier, R. D. Trace fossil assemblages in Upper Silurian tuff beds: evidence of biodiversity in the Old Red Sandstone of southwest Wales, UK. Palaeogeogr. Palaeoclimatol. Palaeoecol. 274, 160-172 (2009).

40. Minter, N. J. et al. in The Trace-Fossil Record of Major Evolutionary Events, Vol. 1. (eds Mángano, M. G. \& Buatois, L. A.) 205-324 (Springer, 2016c).

41. Davies, N. S., Sansom, I. J. \& Turner, P. Trace fossils and paleoenvironments of a Late Silurian marginal-marine/alluvial system: The Ringerike Group (Lower Old Red Sandstone), Oslo Region, Norway. Palaios 21, 46-62 (2006).

42. Buatois, L. A. \& Mángano, M. G. in Microbial Mats in Siliciclastic Sediments, SEPM Spec Pub 101. (eds Noffke, N. \& Chafez, H.) 15-28 (Society for Sedimentary Geology, 2012).

43. Gibling, M. R. \& Davies, N. S. Palaeozoic landscapes shaped by plant evolution. Nat. Geosci. 5, 99-105 (2012).

44. Corenblit, D., Davies, N. S., Steiger, J., Gibling, M. R. \& Bornette, G. Considering river structure and stability in the light of evolution: Feedbacks between riparian vegetation and hydrogeomorphology. Earth Surf. Proc. Land. 40, 189-207 (2015).

45. Davies, N. S. \& Gibling, M. R. The sedimentary record of Carboniferous rivers: Continuing influence of land plant evolution on alluvial processes and Palaeozoic ecosystems. Earth Sci. Rev. 120, 40-79 (2013). 
46. Ward, J. V., Tockner, K., Arscott, D. B \& Claret, C. Riverine landscape diversity. Freshwater Biol.47, 517-539 (2002).

464

465

466

467

468

469

470

471

472

473

474

475

476

477

478

479

480

481

482

483

484

47. Erwin, D. H. A preliminary classification of evolutionary radiations. Hist. Biol. 6, 133147 (1992).

48. Ruta, M., Angielczyk, K. D., Fröbisch, J. \& Benton, M. J. Decoupling of morphological disparity and taxic diversity during the adaptive radiation of the anomodont therapsids. Proc. R. Soc. Lond. B 280, 20131071 (2013).

49. Chloe, J. C. \& Crespi, B. J. The Evolution of Social Behavior in Insects and Arachnids (Cambridge University Press, 1997).

50. Buatois, L. A., Labandeira, C. C., Mángano, M. G., Cohen, A. \& Voigt, S. in The TraceFossil Record of Major Evolutionary Events, Vol. 2. (eds Mángano, M. G. \& Buatois, L. A.) $179-263$ (Springer, 2016).

51. Bertling, M. et al. Names for trace fossils: A uniform approach. Lethaia 39, 265-286 (2006).

52. Minter, N. J., Braddy, S. J. \& Davis, R. B. Between a rock and a hard place: Arthropod trackways and ichnotaxonomy. Lethaia 40, 365-375 (2007).

53. Knaust, D. in Trace-Fossils as Indicators of Sedimentary Environments. (eds Knaust, D. \& Bromley, R. G.) 79-101 (Elsevier, 2012).

54. Alroy, J. et al. Effects of sampling standardization on estimates of Phanerozoic marine diversification. Proc. Natl. Acad. Sci. USA 98, 6261-6266.

55. Smith, A. B. \& McGowan, A. J. The shape of the Phanerozoic marine palaeodiversity curve: How much can be predicted from the sedimentary rock record of Western Europe? Palaeontology 50, 765-774 (2007). 
56. Lloyd, G. T. A refined modelling approach to assess the influence of sampling on palaeodiversity curves: New support for declining Cretaceous dinosaur richness. Biol. Lett. 8, 123-126 (2012).

57. Sakamoto, M., Venditti, C. \& Benton, M. J. 'Residual diversity estimates' do not correct for sampling bias in palaeodiversity data. Methods Ecol. Evol. 8, 453-459 (2017).

58. Ronov, A. B., Khain, V. E., Balukhovsky, A. N. \& Seslavinsky, K. B. Quantitative analysis of Phanerozoic sedimentation. Sediment. Geol. 25, 311-325 (1980).

59. Peters, S. E. Macrostratigraphy of North America. J. Geol. 114, 391-412 (2006).

60. Buatois, L. A., Wisshak, M., Wilson, M. A. \& Mángano, M. G. Categories of architectural designs in trace fossils: A measure of ichnodisparity. Earth-Sci. Rev. 164, 102-181 (2017).

61. Bromley, R. G. Trace Fossils: Biology, Taphonomy and Applications (Chapman and Hall, 1996).

62. Bambach, R. K., Bush, A. M. \& Erwin, D. H. Autecology and the filling of ecospace: Key metazoan radiations. Palaeontology 50, 1-22 (2007).

63. Bush, A. M., Bambach, R. K. \& Daley, G. M. Changes in theoretical ecospace utilization in marine fossil assemblages between the mid-Paleozoic and late Cenozoic. Paleobiology 33, 76-97 (2007).

64. Ausich, W. I. \& Bottjer, D. J. Tiering in suspension-feeding communities on soft substrata throughout the Phanerozoic. Science 216, 173-174 (1982).

65. Bottjer, D. J. \& Ausich, W. I. Phanerozoic development of tiering in soft-substrate suspension-feeding communities. Paleobiology 12, 400-420 (1986).

66. Mángano, M. G. \& Buatois, L. A. Decoupling of body-plan diversification and ecological structuring during the Ediacaran-Cambrian transition: evolutionary and geobiological feedbacks. Proc. R. Soc. B 281, 20140038 (2014). 
67. Buatois, L. A. \& Mángano, M. G. Ichnology: Organism-Substrate Interactions in Space and Time (Cambridge University Press, 2011).

68. François, F., Poggiale, J.-C., Durbec, J.-P. \& Stora, G. A new approach for the modeling of sediment reworking induced by a macrobenthic community. Acta Biotheoretica 45, 295319 (1997).

69. François, F., Gerino, M., Stora, G., Durbec, J.-P. \& Poggiale, J.-C. Functional approach to sediment reworking by gallery-forming macrobenthic animals: Modeling and application with the polychaete Nereis diversicolor. Mar. Ecol. Prog. Ser. 229, 127-136 (2002).

70. Solan, M. \& Wigham, B. D. in Interactions Between Macro- and Microorganisms in Marine Sediments, Coastal and Estuarine Studies 60 (eds Kristensen, E., Haese, R. R. \& Kostka, J. E.) 105-124 (American Geophysical Union, 2005).

71. Buatois, L. A. \& Mángano, M. G. in Trace Fossils: Concepts, Problems, Prospects (ed Miller, W. III) 285-323 (Elsevier, 2007).

72. Buatois, L. A., Mángano, M. G., Maples, C. G. \& Lanier, W. P. The paradox of nonmarine ichnofaunas in tidal rhythmites: Integrating sedimentologic and ichnologic

\section{Methods}

Material. Data (Supplementary Table 3) were obtained from compilations of marginalmarine to continental trace-fossil occurrences for the Ediacaran to Ordovician ${ }^{14}$ and Silurian to Permian ${ }^{40}$. Analyses are restricted to biogenic sedimentary structures that resulted from behavioural interactions between animals and sediments and excludes structures produced by plants and fungi. Assignment of trace fossil occurrences to particular environmental 
interpretations were adjusted based on information in additional primary literature sources.

536 Regional chronostratigraphy in the primary literature was converted to International

537 Chronostratigraphic divisions ${ }^{14,40}$. Uncertainty in temporal designations is negated by our use

538 of analyses at the level of the geological period. Ichnotaxonomic assignments were revised

539 where necessary in the source compilations ${ }^{14,40}$ with reference to monographic treatments and

540 other substantial ichnotaxonomic works. Often, ichnotaxa are inherently long ranging and

541 many of the ichnogenera found in the Cambrian are present throughout the rest of the

542 Palaeozoic and extend to more recent time. Few ichnotaxa are restricted to only one

543 geological period. Ichnotaxonomic principles have undergone a period of rationalization ${ }^{51-53}$

544 and, coupled with the above patterns, the effects of differences in ichnotaxonomic practices

545 amongst researchers are likely to be minimized. For each geological period and

546 environmental category, global raw counts were obtained for each of the following

547 diversification metrics: ichnodiversity, ichnodisparity, ecospace occupation, and ecosystem

548 engineering. Ichnodiversity and ichnodisparity are quantified respectively as the numbers of

549 ichnogenera and architectural designs. Ecospace occupation is quantified as the number of

550 modes of life, and ecosystem engineering as the number of impacts upon the sediment.

551 Raw counts were used to enable identification of patterns of appearance and also

552 potential disappearance and reappearance of behavioural strategies, modes of life, and

553 impacts upon the sediment. Range-through data may be used to ameliorate the effects of a

554 patchy body-fossil record because species cannot re-evolve and so must be present in

555 between their first and last appearances. However, the trace-fossil record is a different entity

556 in this regard. A variety of organisms can make the same ichnotaxon by performing the same

557 behaviour, and the same organism can make different ichnotaxa by performing different

558 behaviours. As such, ichnotaxa are generally long-ranging but there may be valid gaps in

559 their record. If a particular ichnotaxon disappears from an environment for an interval of 
time, it may reappear in younger strata if the environment is re-colonised by a producer that had sought a temporary refugium or, alternatively, the responsible behavioural programme could re-evolve by convergence or parallelism in a different organism. The use of raw counts enables the identification of a behavioural programme or mode of life that disappears from a particular environment. An example is disappearance resulting from an extinction event,

565 followed by subsequent reappearance during the recovery interval. Consequently, keystone functions performed by organisms and resulting patterns of ecological succession may be assessed.

Potential biasing factors in the continental and shallow marginal-marine trace-fossil record. Sub-sampling ${ }^{54}$ and residual diversity estimates ${ }^{55,56}$ are the two principal methods for controlling the patchiness of the fossil record when analyzing patterns of diversity through time. The sub-sampling method involves randomly drawing a pre-determined sub-sample of fossil assemblages from a pool for each time bin in order to produce a normalized diversity curve $^{54}$; whereas the residual diversity estimate method involves a comparison of observed diversity values to a null model in order to find the residuals for producing a de-trended diversity curve ${ }^{55,56}$. Sub-sampling is best performed with large sample sizes, whereas the residuals method does not require a large sample size ${ }^{56}$. As our data are sample-limited, with

578 fewer than 10 trace-fossil bearing formations or trace-fossil assemblages for some time

579 intervals and environments, we employed the underlying principles of the residuals method over the sub-sampling method. The algorithms developed for producing de-trended diversity

581 curves from residuals have been questioned ${ }^{57}$. However, the principle of testing for

582 correlations between diversity and sampling measures and obtaining residuals of observed

583 values from a null model is valid as a test of the quality of the fossil record. Potential sampling biases on observed diversification metrics were tested using Spearman Rank-Order 
585 Correlation. Normality tests are unreliable for relatively small samples of observations and so 586 the non-parametric Spearman Rank-Order Correlation was used because it does not assume

587 that data are normally distributed. The potential sampling biases that were considered were:

588 terrestrial clastic rock volume ${ }^{58}$, the number of trace-fossil bearing formations, and the

589 number of trace-fossil assemblages. The former is an independent measure of the rock record

590 and the latter two are likely to be dependent to some degree with observed diversification

591 metrics $^{30}$. More recent compilations of rock volume exist but are not used in our analysis

592 because they are restricted geographically to North America ${ }^{59}$ and Western Europe ${ }^{55}$. Trade-

593 offs between the influence of sampling biases and the temporal resolution of identified

594 patterns were investigated by testing for rank-order correlations between each of the potential

595 sampling biases and ichnodiversity counts for data pooled at the levels of the geological

596 period and geological sub-period. For the sub-period analysis, when testing for correlations

597 with the numbers of trace-fossil bearing formations and trace-fossil assemblages, the data

598 were separated into the following time bins: Ediacaran, early Cambrian, middle-upper

599 Cambrian, Early Ordovician, Middle Ordovician, Late Ordovician, Silurian, Early Devonian,

600 Middle Devonian, Late Devonian, Mississippian, Pennsylvanian, Early Permian, and Late

601 Permian. Ordovician sub-period data were pooled when testing for a correlation with

602 terrestrial clastic rock volume in order to relate them to this dataset ${ }^{58}$. Analyses were

603 conducted for subaqueous coastal, transitional coastal, and transitional alluvial environments

604 because they have the most complete trace-fossil records. There are three repeated

605 comparisons (for the three environments) for each of the comparisons of a sampling measure

606 and diversity index, and so we apply a Bonferroni corrected $\alpha$ '-level for multiple

607 comparisons $=0.0167$. Data and patterns for other environments are presented for

608 completeness in the supplementary material (Supplementary Figs 1-6).

609 
610 Analytical frameworks. We use trace fossils as a unit of measurement and incorporate them

611 into the frameworks for macroevolutionary analysis of behavioural diversification ${ }^{28,60}$,

612 ecospace occupation, and ecosystem engineering ${ }^{29}$ during evolutionary radiations. Trace

613 fossils provide in situ evidence and precise environmental contexts of animals for revealing

614 the timing, routes ashore, and initial colonization of different continental environments.

615

616 Behavioural diversification. Analysis of behavioural diversification is based upon

617 comparisons of ichnodiversity and ichnodisparity ${ }^{28,60}$. Ichnodiversity is a measure of

618 ichnotaxonomic richness. Ichnotaxa are biogenic sedimentary structures that are produced by

619 behavioural interactions between organisms and their inhabited substrates ${ }^{51}$. They are

620 classified on the basis of their morphology, which is the product of the anatomy of the

621 producer, its behaviour, and the substrate ${ }^{52}$. A variety of organisms may produce the same

622 ichnotaxon by performing the same behaviour; equally, the same organism may produce

623 different ichnotaxa by performing different behaviours or by interacting with different

624 substrates, or both ${ }^{61}$. Ichnodisparity is a measure of the variability of trace-fossil

625 morphological plans, quantified as the number of architectural designs such as simple

626 horizontal trails or vertical unbranched burrows ${ }^{28,60}$. Architectural designs reflect broad

627 behavioural programmes, within which there may be variations represented by different

628 ichnotaxa. There are a variety of many-to-one relationships between ichnogenera and

629 architectural designs.

630

631 Ecospace occupation. The amount of occupied ecospace is quantified as the number of

632 modes of life, categorized on the basis of three parameters: (i) tiering, subdivided into

633 surficial, semi-infaunal, shallow infaunal, intermediate infaunal, and deep infaunal tiers; (ii)

634 motility, subdivided into motile, facultatively motile, and non-motile types; and (iii) feeding 
mode, subdivided into suspension feeders, non-specialized deposit feeders, specialized deposit feeders, predators, and others. There are a variety of one-to-one, many-to-one and one-to-many relationships between ichnogenera and modes of life. In the latter case, an ichnogenus may have more than one possible tier and feeding mode. Architectural designs have one-to-one, one-to-many and many-to-one relationships with modes of life. trace fossil to form, an animal must interact with a substrate. Therefore, the realm of tracefossil analysis largely is restricted to those organisms at or below the sediment surface. However, there are exceptions: for example, terrestrial animals such as termites may construct a structure above ground and animals may interact with substrates that are above ground, such as soil nests lodged on plants, or with mobile substrates such as logs. For the purposes of this analysis of subaqueous to subaerial habitats, tiering categories are limited to occurrences at or below the sediment surface. Surficial tier animals are those living on the sediment surface and not extending significantly upward, whereas semi-infaunal tier animals are partly infaunal and exposed to the overlying water or air $^{62,63}$. Trace fossils provide direct information on the life positions of animals, and so it is possible to be rather precise regarding infaunal tiering levels. The system adopted here comprises a shallow infaunal tier for depths up to $6 \mathrm{~cm}$ from the upper substrate surface, an intermediate infaunal tier for depths of 6 to $12 \mathrm{~cm}$, and a deep infaunal tier for depths of greater than $12 \mathrm{~cm}^{64-66}$. This allows for the differentiation of an intermediate tier and a truly deep tier of infaunal animals. occupation developed for body fossils have defined three major levels of motility: motile, 658 facultatively motile and non-motile, each with two sublevels of fast and slow ${ }^{62,63}$. This 
analysis restricts categorization of motility to the three higher levels. Facultatively motile animals are those that are generally stationary but are capable of movement.

662 feeders are those that obtain and capture food particles from the water column. Deposit

663 feeders are those that actively ingest particles of food from a substrate. To avoid spatial segregation, the deposit-feeder category is used in a broad sense to include those organisms that obtain their food from the surface, are buried within the substrate, or feed by grazing (categories of surface deposit feeding, mining, and grazing ${ }^{62,63}$ ). Nevertheless, deposit feeders are categorized on the basis of trace-fossil morphology into non-specialized deposit feeders with non-patterned and overcrossing trails, and specialized and systematic deposit feeders with patch exploration and non-overcrossing locomotory motifs. Predators are those tracemakers inferred to have been able to capture prey. The final category of 'other' includes chemosymbiosis as suggested for Chondrites; as well as farming activities as exemplified by complex, regular, patterned, meandering, spiral, radiating and network trace fossils known as graphoglyptids.

675 Ecosystem engineering. The amount of ecosystem engineering is quantified as the number

676 of impacts on a sedimentary stratum, based on three parameters: tiering (as above); the

677 mechanisms by which organisms interact with the sediment (intrusion, compression,

678 backfilling, and excavation); and the basic modes by which production of a trace fossil

679 modifies the sediment (biodiffusion, gallery biodiffusion, conveyors, and regenerators).

680 There are a variety of one-to-one, many-to-one and one-to-many relationships between

681 ichnogenera and the impacts upon a sedimentary stratum. In the latter case, an ichnogenus

682 may have more than one possible tier. Architectural designs may have one-to-one, one-tomany and many-to-one relationships with the impacts upon a sedimentary stratum. Modes of 
684 life may have one-to-one, many-to-one and one-to-many relationships with impacts upon a

685

686

687

688

689

690

691

692

693

694

695

696

697

698

699

700

701

702

703

704

705

706

707 708 sedimentary stratum.

Animals may interact with a substrate by four principal means: intrusion, compression, backfilling, and excavation ${ }^{61,67}$. Intrusion involves displacement of sediment as the animal moves through, resulting in the modified sediment closing-up behind the motile organism. Compression involves the movement and compaction of sediment around the animal as it passes through. Backfilling involves the active backward passage of sediment either around or through the animal. Excavation consists of the active loosening and transport of sediment from one location to another ${ }^{61,67}$.

Categorization of the modes in which production of a trace fossil modifies the sediment used in this analysis are borrowed and adapted from concepts developed by marine benthic ecologists ${ }^{68-70}$. As well as being well suited for this purpose, this approach fosters commonality of language between ichnologists and benthic ecologists. In this analysis, consideration of modes of sediment modification is limited to biodiffusion, gallery biodiffusion, conveyors, and regenerators ${ }^{68-70}$. Biodiffusion is the movement of sediment particles over short distances, whereas gallery biodiffusion involves the rapid redistribution of sediment particles from one part of the sediment profile to another ${ }^{68-70}$. Upward and downward conveyors ${ }^{68,70}$ are subsumed within the simpler concept of conveyors, with animals also able to convey sediment laterally. This category refers to animals that actively transport sediment particles across and within tiers. Regenerators are animals that actively move sediment to the surface from below, where it may be transported away by physical sedimentary processes such as currents ${ }^{68,70}$. Categories of epifaunal bioturbators and surficial modifiers ${ }^{70}$ are omitted because of their spatial constraints, and are covered potentially by any of the other four means of sediment reworking in the epifaunal and semi-infaunal tier. Sediment reworking categories relate to movement of particles within fluids, and so are 
applicable to scenarios where the ambient medium is water or air. There are constraints on

711 modification and interactions with the sediment tend to go together, such as excavation and

712 regeneration, whereas others are unlikely to go together, such as backfilling and gallery

713 biodiffusion.

714

715 Environmental framework. Three principal environmental settings were considered in this 716 analysis: (i) coastal, (ii) alluvial, and (iii) lacustrine. Each of these categories may be further 717 subdivided in order to reflect an environmental or ecological gradient from those that are: (a)

718 permanently subaqueous, (b) transitional between subaqueous and subaerial within a

719 confined stratigraphic interval, or (c) subaerially exposed ${ }^{14}$. This generates both a seaward-to-

720 landward gradient and an additional gradient based upon the availability of water. The three categories included within coastal settings of subaqueous, transitional and subaerial can be understood as reflecting an environmental gradient along a coastal plain. The

723 first two categories reflect for the most part the activity of brackish-water faunas. Fjord areas are affected by strong freshwater discharge, whereas tidal flats from the innermost zones of estuarine systems formed between the maximum landward limit of tidal influence and the maximum landward limit of the marine saline wedge. Both therefore represent a departure

727 from typical marginal-marine conditions because they host freshwater faunas ${ }^{71,72}$. The

728 subaerial category reflects the activity of terrestrial biotas. The three categories included within alluvial settings (subaqueous, transitional, subaerial) also illustrate a gradient from active channels to riparian overbank settings and ultimately zones affected by aeolian

731 processes. This is more an ecological gradient than an environmental gradient because 732 aeolian depositional systems are not necessarily associated with riverine systems. The 733 subaqueous category reflects the activity of freshwater biotas, while the transitional one 
accommodates the work of freshwater to terrestrial faunas. The subaerial category reflects the

735

736

737

738

739

740

741

742

743

744

745

746

747

748

749

750

751

752

753

754

755

756

757 work of fully terrestrial animals. The three categories included within lacustrine settings (subaqueous, marginal, ephemeral) illustrate an ecological gradient, from fully subaqueous settings to lake margins affected by a fluctuating water table and ultimately to ephemeral water bodies that experienced longer periods of subaerial exposure. While the first two categories reflect adjacent environments within a depositional system, the latter typically illustrates arid to semi-arid conditions that occur in the context of aeolian or ephemeral fluvial systems.

Ordination of behavioural and ecological diversification. The constituent components of ichnodisparity, ecospace occupation, and ecosystem engineering that occur through time intervals of occupation of subaqueous coastal, transitional coastal, and transitional alluvial environments were investigated using principal co-ordinate analyses. Data analyzed were separate presence-absence matrices for each of: (i) architectural designs, (ii) modes of life, and (iii) impacts upon the sediment (Supplementary Tables 4-6). The Jaccard index was used as the similarity measure due to the binary nature of the data, and because it was computed on shared occurrences.

\section{Acknowledgements}

Financial support for the initial part of this project was provided to N.J.M. through a Government of Canada Post-doctoral Research Fellowship under the Canadian Commonwealth Scholarship Program. Additional funding was provided by the Natural Sciences and Engineering Research Council (NSERC) Discovery Grants 311726-05/08/15 and 311727-05/08/13 (to L.A.B. and M.G.M. respectively). M.R.G also acknowledges funding from an NSERC Discovery Grant. This is Earth Sciences Sector contribution number 
National Museum of Natural History, Washington D.C. We are grateful for the constructive comments of the editor, two anonymous reviewers and Russell Garwood that improved the manuscript.

Data availability. All datasets generated or analysed during this study are included in this published article (and its supplementary information files).

Author contributions. N.J.M., L.A.B. and M.G.M. conceived the study. N.J.M., L.A.B., M.G.M., N.S.D., M.R.G., R.B.M. and C.C.L. contributed data to the analysis. N.J.M. performed the analysis and analysed the results. N.J.M. led the writing of the paper, with inputs from the other authors.

Conflicts of interest. The authors declare no conflicts of interest.

Figure 1 I Colonization of subaqueous coastal environments (estuaries and shallow subtidal flats) through the Ediacaran to Permian periods. (a) Ecospace occupation. (b) Ecosystem engineering. (c) Plot of changes in ichnodiversity, ichnodisparity, ecospace occupation and ecosystem engineering. Ichnodiversity and ichnodisparity are global counts of the numbers of ichnogenera and architectural designs by geological period. Ecospace occupation and ecosystem engineering are quantified, respectively, as the global number of modes of life and number of different ichnological impacts upon the sediment during each geological period. Counts are cumulative for each geological period and therefore plotted at the end of the intervals. 
784 Figure 2 Colonization of transitional coastal environments (coastal plains and tidal

785 flats) through the Ediacaran to Permian periods. (a) Ecospace occupation. (b) Ecosystem

786 engineering. (c) Plot of changes in ichnodiversity, ichnodisparity, ecospace occupation and

787 ecosystem engineering.

788

789 Figure 3 | Colonization of transitional alluvial environments (floodplains and

790 abandoned channels) through the Ediacaran to Permian periods. (a) Ecospace

791 occupation. (b) Ecosystem engineering. (c) Plot of changes in ichnodiversity, ichnodisparity, 792 ecospace occupation and ecosystem engineering.

793

794 Figure 4 | Number of global ichnogenera per global architectural design occupying

795 different tiers through time in different environments. (a) Subaqueous coastal

796 environments. (b) Transitional coastal environments. (c) Transitional alluvial environments. 


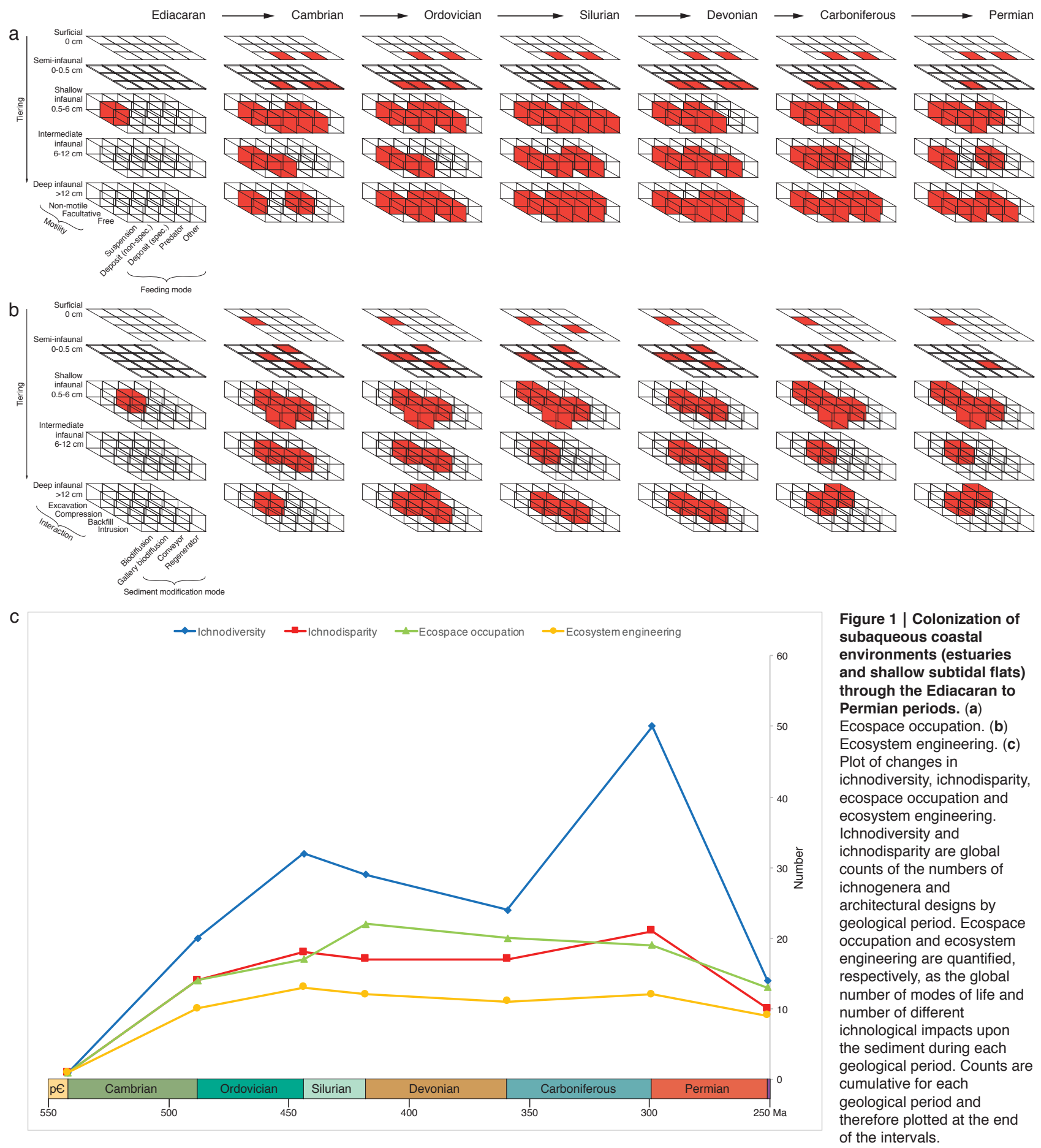




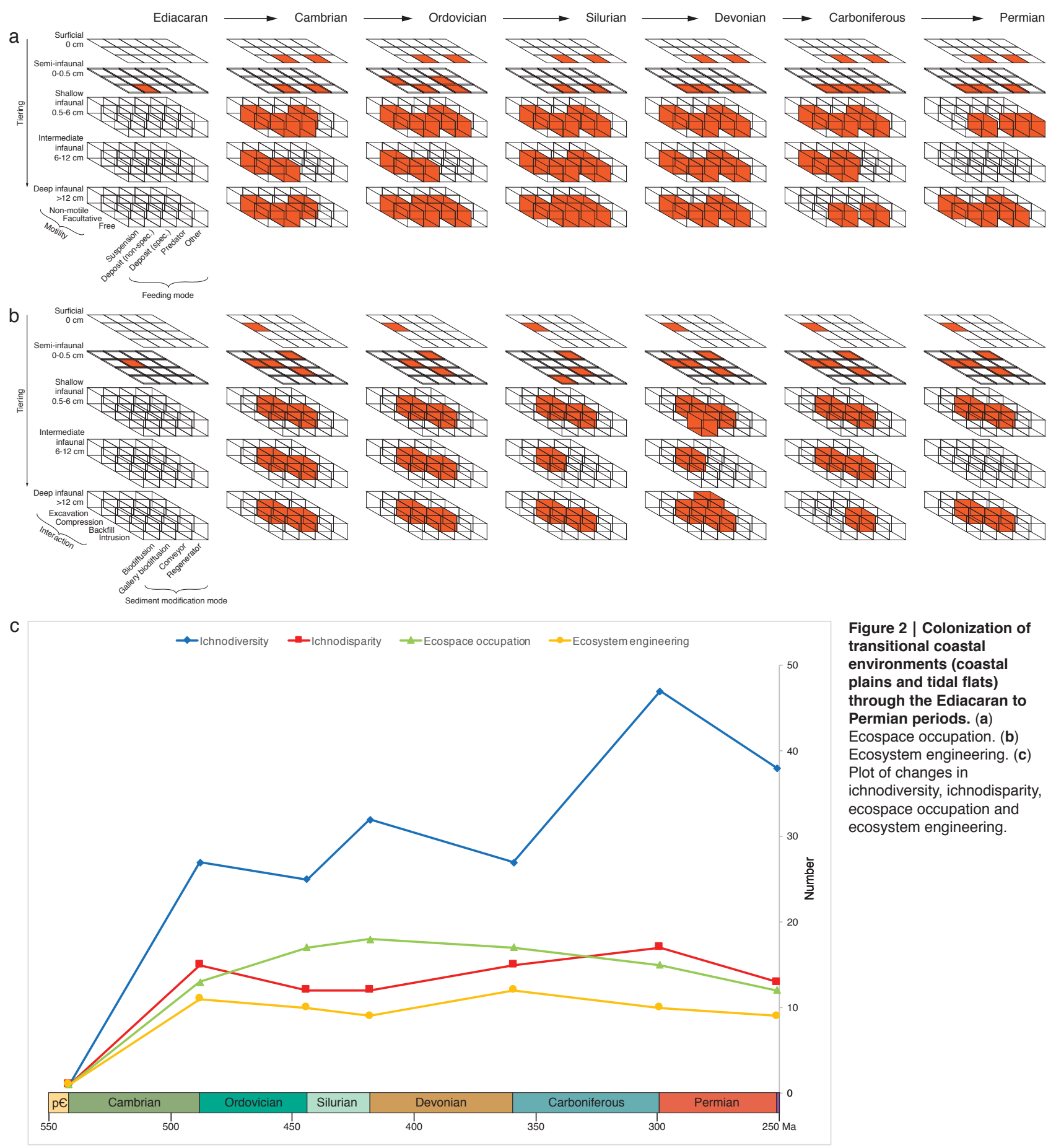




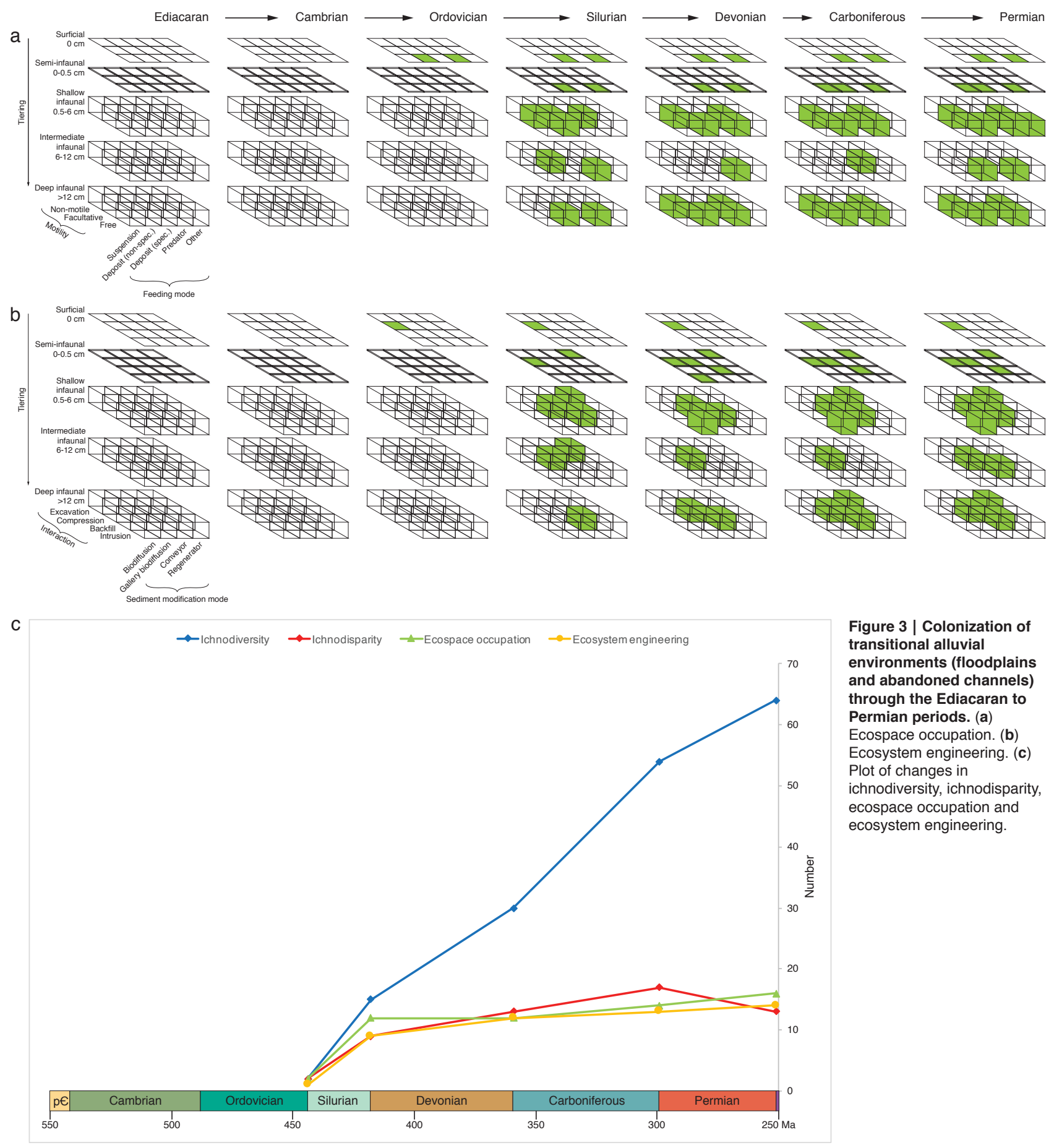


a
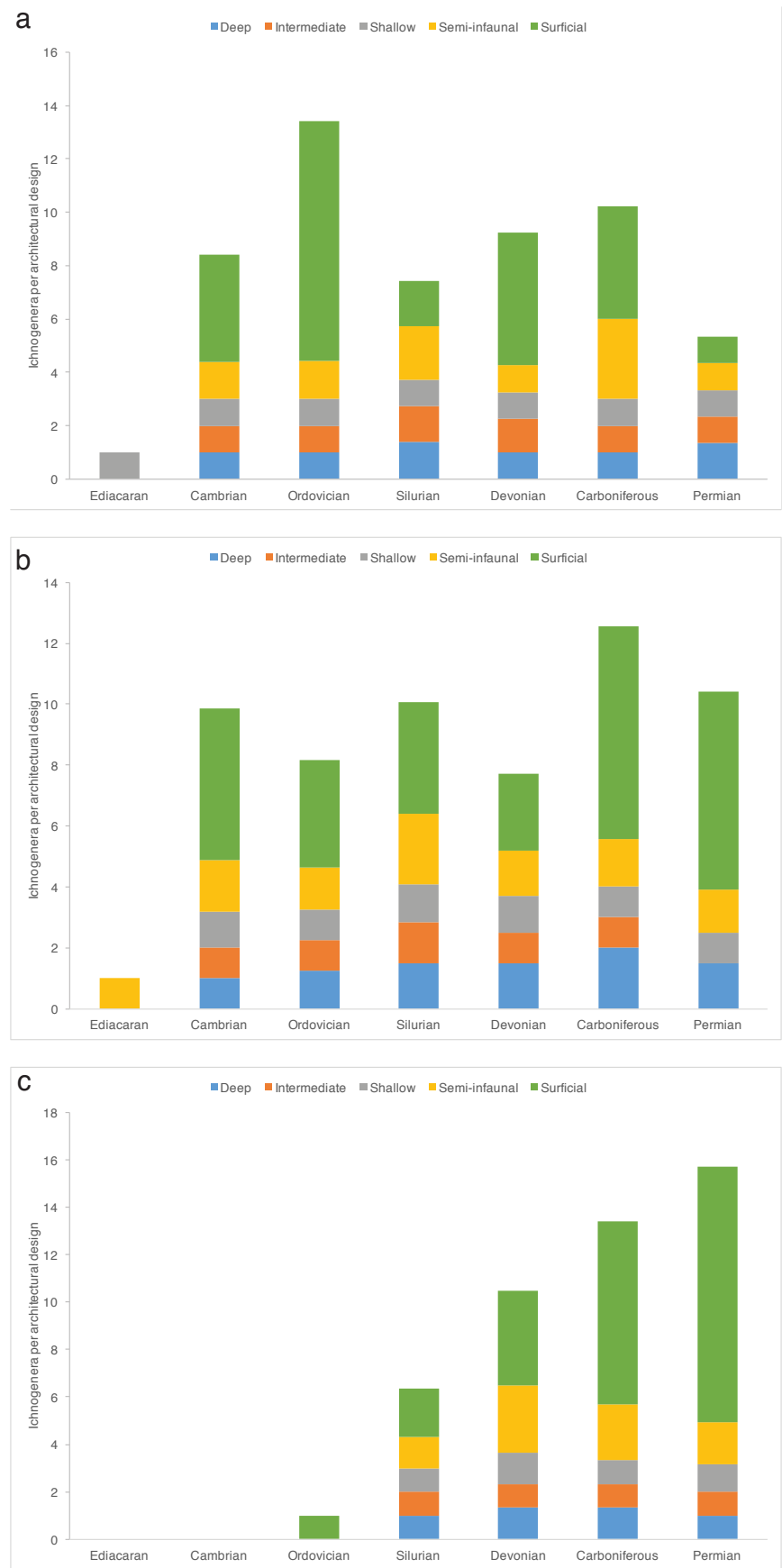

Figure 4 | Number of global ichnogenera per global architectural design occupying different tiers through time in different environments. (a) Subaqueous coastal environments. (b) Transitional coastal environments. (c) Transitional alluvial environments. 